\title{
RELATIONSHIP BETWEEN VESSEL PARAMETERS AND CLEAVAGE ASSOCIATED WITH CHECKING IN Eucalyptus grandis WOOD
}

\author{
Bruno Charles Dias Soares ${ }^{1, \star}$ \\ http://orcid.org/0000-0002-6739-3529 \\ José Tarcísio Lima ${ }^{1}$ \\ http://orcid.org/0000-0002-3513-9198 \\ José Reinaldo Moreira da Silva ${ }^{1}$ \\ https://orcid.org/0000-0002-1723-8512
}

\begin{abstract}
In this work, the relationship between vessels parameters and the wood cleavage strength were studied to clarify the process of formation of this type of check, very common in Eucalyptus wood. The objective was to identify the relationship between the wood cleavage strength, the average area of the vessel, and the percentage area of vessels on the wood transverse surface. For this, two Eucalyptus grandis trees at 22 years old were felled and specimens for the cleavage test were produced to determine the wood cleavage strength. From these specimens, samples were taken to determine the average area of the vessel and the percentage area of vessels, aiming at adjusting mathematical models that explain the variation in the cleavage strength. The results showed that the higher the average area of the vessel and the percentage of area occupied by vessels in the wood, the lower its cleavage strength. The multiple linear regression model can estimate the cleavage strength as a function of the average area of the vessel, and the percentage area of the vessels.
\end{abstract}

Keywords: Cleavage strength, Eucalyptus grandis, vessels area, wood anatomy, wood fractures, wood mechanical strength.

\section{INTRODUCTION}

As a sustainable alternative to the use of wood from Brazilian native species for the sawn timber industry, species of the genus Eucalyptus have been used. However, this wood is prone to defects caused by the release of growth stress and the stresses generated during the drying process. The presence of checks is a negative factor for the sawn timber production sector, resulting in loss of sawn yield, less possibilities for use, and consequently, loss of commercial value.

Wood is anatomically composed of fibers, vessels, and parenchymal cells, with the function of supporting the tree, conducting the raw sap, and storing nutrients, respectively. The existence of the vessels characterize wood as a porous material, the fiber cell wall being responsible for the mechanical strength of the trunk. The stresses applied to the wood dissipate through the cell walls, which in turn can deform elastically, plastically, or undergo fracture, depending on their mechanical strength and the type and the degree of applied stress. 
The classic mechanics equations indicate that if the frequency of the orifices is higher in a porous solid, the stress concentration factor also increases (Mattheck and Kubler 1997). This is because the pores are discontinuities considered as failures that do not offer mechanical resistance to stresses applied to the solid. Thus, the higher the porosity, the higher the concentration of stresses on the solid structure of the material and the higher the probability of fractures occurring (Ugural and Fenster 1995, Craig 2011, Sanford 2003). In wood, the pores are the vessels seen in the transverse plane, that is, the higher the concentration of vessels, the higher the chances of fracture occurring in the material.

According to the mechanics of solids (Ugural and Fenster 1995, Craig 2011, Sanford 2003), the maximum tangential stress generates the wedge effect on the structure of solid wood, starting the fracture from the geometric center of the vessel. Sanford (2003) indicates that the resulting stress, perpendicular to the direction of the original stress at the orifice edge, is about three times higher than the maximum tangential stress applied to the porous solid.

Gacitúa et al. (2007) analyzed samples taken from wood discs, both with and without checks, in Eucalyptus nitens at 16 years of age. They observed that the average area of the vessel was higher in the samples with visible checks than in the samples without visible checks. Valenzuela et al. (2012a) analyzed the checks and characteristics of the vessels in 12-year-old E. nitens wood samples and found a higher vessels diameter and higher average area of vessels in the wood with a higher percentage of checks. Soares et al. (2019), studying the juvenile wood and the mature wood of E. cloeziana at the age of 37 years, stated that the lower vessel frequency and higher vessel diameter found in mature wood were associated with a lower occurrence of end checks.

It is possible to observe in logs or pieces of sawn wood that the checks that occur due to the release of growth stresses, and/or as a consequence of the drying process, most often follow the notations $\mathrm{I}_{T R}$ and $\mathrm{I}_{T L}$ (Bodig and Jayne 1982). This means that the stresses occur mainly in the cleavage mode, with stress that causes the check opening following the tangential direction, and the propagation front following the radial $\left(\mathrm{I}_{T R}\right)$ or longitudinal $\left(\mathrm{I}_{T L}\right)$ direction. Thus, it is believed that the wood may be more prone to checking when the material is less resistant when subjected to cleavage testing.

In this context, the objective of this work was to contribute to clarifying the relationship between the wood mechanical cleavage strength, the average area of the vessel, and the percentage area of vessels.

\section{MATERIAL AND METHODS}

\section{Material origin and collection}

Two 22-year-old Eucalyptus grandis trees were selected among those present in an experimental planting on the campus of the Federal University of Lavras, located in the municipality of Lavras - MG, latitude $2^{\circ} 14$ '4" south and longitude $44^{\circ} 59^{\prime} 5^{\prime \prime}$ 'west.

The material biometric characterization was performed by measuring the diameter at breast height (DBH), total height, and commercial height of the logs to be sawn, considering up to a minimum diameter of $20 \mathrm{~cm}$. This diameter was set to allow the specimens for mechanical tests to be prepared from the central planks that were obtained after sawing the logs.

\section{Cleavage mechanical test}

The base logs were chosen ( $0 \mathrm{~m}$ to $3 \mathrm{~m}$ height) and cross-sectioned to obtain 1,5 $\mathrm{m}$ length small logs. The option for the base logs was based on the hypothesis that this region better represents the wood properties for the whole tree, considering old trees (Downes et al. 1997). From the logs, central planks were obtained using a vertical band saw by the alternate method and parallel to the log center. The central planks of each tree were sawn to make 25 specimens per tree. The production of defect-free specimens followed the suggestions of the ASTM D143-14 (2014), without distinction of heartwood and sapwood, or juvenile wood and mature wood. The cleavage mechanical test was performed using a universal testing machine EMIC, model DL 30000. The specimens were tested in the green condition.

It was decided to produce the specimens in such a way that the cleavage occurred in the direction of the 
rays, aiming at the provocation of checks of the $\mathrm{I}_{T L}$ type. This method was chosen taking into account that the checks occur more frequently in the direction of the rays $\left(\mathrm{I}_{T R}\right.$ and $\mathrm{I}_{T L}$ types - Bodig and Jayne 1982).

\section{Vessels parameters analysis}

Among the 50 specimens tested, 30 were selected (10 more resistant, 10 intermediate resistant, and 10 less resistant) for the production of cubes with approximately $1 \mathrm{~cm}^{3}$, used in the analysis of the vessels seen in the transverse plane. The cubes were removed in the region close to the check, as shown in Figure 1.

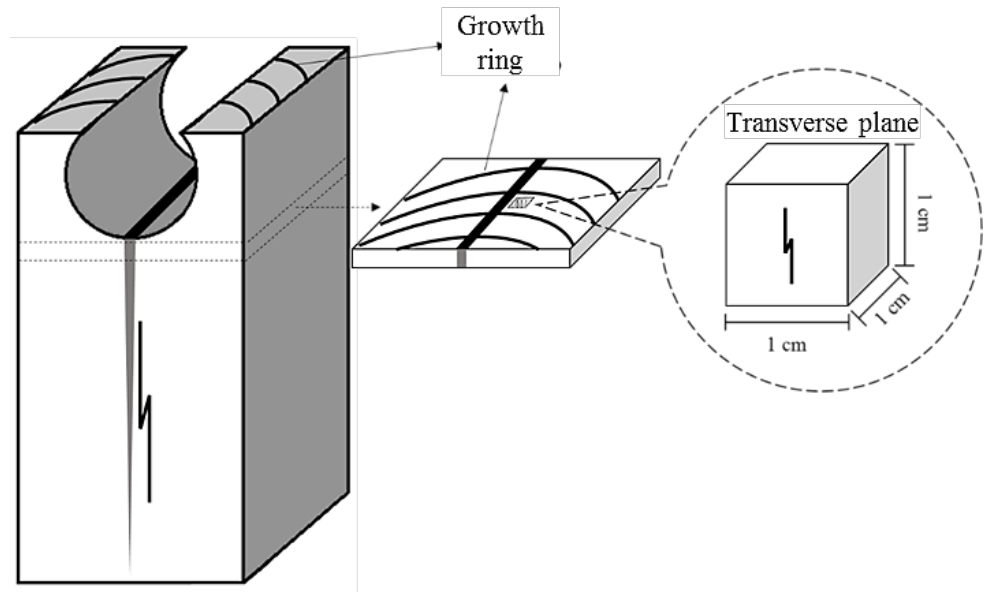

Figure 1: Representation of the samples preparation for the light stereomicroscope analysis.

Using the light stereomicroscope with a coupled camera, images of the wood transverse plane were obtained, called areas of interest.

The images were binarized with the aid of the ImageJ software (2019) so that the vessels were black and other areas white. Analyzing the binary images, the measurement of the areas occupied by vessels in each area of interest was performed also using the ImageJ software.

In this study, the "average area of the vessel" (AAV) per sample was measured (Gacitúa et al. 2007, Valenzuela et al. 2012a) and calculated using Equation 1. The percentage of area occupied by vessels on the wood transverse surface was also measured, and this variable is here called the "percentage area of vessels" (PAV). The PAV was calculated using Equation 2.

$$
\mathrm{AAV}=\left[\frac{\left(\frac{\sum A V_{1}}{n_{1}}\right)+\left(\frac{\sum A V_{2}}{n_{2}}\right)+\left(\frac{\sum A V_{3}}{n_{3}}\right)}{3}\right]
$$

Where: $\mathrm{AAV}=$ average area of the vessel of one sample $\left(\mu \mathrm{m}^{2}\right) ; \mathrm{AV}=$ area of one entire vessel present on an area of interest measuring $1,12 \mathrm{~mm}^{2}\left(\mu \mathrm{m}^{2}\right) ; \mathrm{n}=$ Number of entire vessels present on the area of interest that measures $1,12 \mathrm{~mm}^{2}$. 


$$
\mathrm{PAV}=\left[\frac{\left(\frac{\sum A V_{1}}{1,12}\right) \times 100+\left(\frac{\sum A V_{2}}{1,12}\right) \times 100+\left(\frac{\sum A V_{3}}{1,12}\right) \times 100}{3}\right]
$$

Where: $\mathrm{PAV}=$ percentage area of vessels of one sample $(\%) ; \mathrm{AV}=$ area that one vessel occupies on the area of interest that measures $1,12 \mathrm{~mm}^{2}\left(\mathrm{~mm}^{2}\right) ; 1,12=$ area of interest $\left(\mathrm{mm}^{2}\right)$.

Three different areas of interest, approximately $1,12 \mathrm{~mm}^{2}$ each, were analyzed on the transverse surface of each wood sample. Thus, AAV and PAV per sample were obtained by averaging these three areas (repetitions), as shown in Equation 1 and Equation 2.

\section{Data statistical analysis}

Initially, the data of wood cleavage strength, the average area of the vessel (AAV), and percentage area of vessels (PAV) were subjected to descriptive statistical analysis to assess the averages and data variation.

Simple regression analyzes were performed to adjust models in order to explain the behavior of cleavage strength as a function of the AAV and the PAV for the evaluated samples. Multiple regression analyzes were also carried out to adjust models capable of predicting the cleavage strength using the vessel parameters mentioned as a basis.

\section{RESULTS AND DISCUSSION}

Table 1 presents the results of the descriptive statistical analysis performed for the data of cleavage strength, the average area of the vessel (AAV), and the percentage area of vessels (PAV).

Table 1: Descriptive statistical analysis of the properties of $E$. grandis wood sampled at 22 years of age.

\begin{tabular}{|c|c|c|c|c|c|}
\hline Property & $\mathrm{n}$ & Maximum & Average & Minimum & CV \% \\
\hline Cleavage strength $(\mathrm{MPa})$ & 50 & 0,86 & 0,64 & 0,44 & 16,00 \\
\hline Average area of the vessel $\left(\mu \mathrm{m}^{2}\right)$ & 30 & 16556 & 12493 & 8238 & 18,47 \\
\hline Percentage area of vessels $(\%)$ & 30 & 27,0 & 18,7 & 13,3 & 20,46 \\
\hline
\end{tabular}

$\mathrm{n}=$ number of analyzed specimens; $\mathrm{CV} \%=$ coefficient of variation in percentage.

The average cleavage strength of $0,64 \mathrm{MPa}$ is higher than the average found by Araújo (2007), of 0,57 $\mathrm{MPa}$, calculated from the values for 115 Brazilian tropical species. The cleavage strength values seen in Table 1 are within the range found by Dias and Lahr (2004), who found cleavage strength averages ranging between $0,40 \mathrm{MPa}$ and 2,00 MPa for the 40 hardwood species analyzed in their study.

About the AAV, the average of $12493 \mu \mathrm{m}^{2}$ is higher than that found by Barotto et al. (2017), of 9673 $\mu \mathrm{m}^{2}$, in wood of four $E$. grandis clones analyzed at 18 years of age. This may be related to the age difference between the materials evaluated, in addition to the influence of the possible difference in water availability at different sites which affects vessel dimensions (Carlquist 2001).

With regard to PAV, the average of $18,7 \%$ is higher than the average of $14,4 \%$ found by Barotto et al. (2017), indicating that the average area of the vessel tends to directly influence the percentage area of the vessels. 
Equation 3 and Equation 4 show the models adjusted for cleavage strength as a function of AAV and PAV, respectively. This data's behavior is also illustrated in Figure 2 and Figure 3, respectively.

$$
\begin{gathered}
f_{s 0}=\left[-0,0325046+\left(6052,16\left(\mathrm{AAV}^{-1}\right)\right)\right]^{0,5} \\
f_{s 0}=[1,69662-(0,305118(\ln \mathrm{PAV}))]^{2}
\end{gathered}
$$

The coefficient of determination $\left(\mathrm{R}^{2}\right)$ of the regressions for cleavage strength as a function of $\mathrm{AAV}$, and for cleavage strength as a function of PAV, were 0,546 and 0,538 respectively.

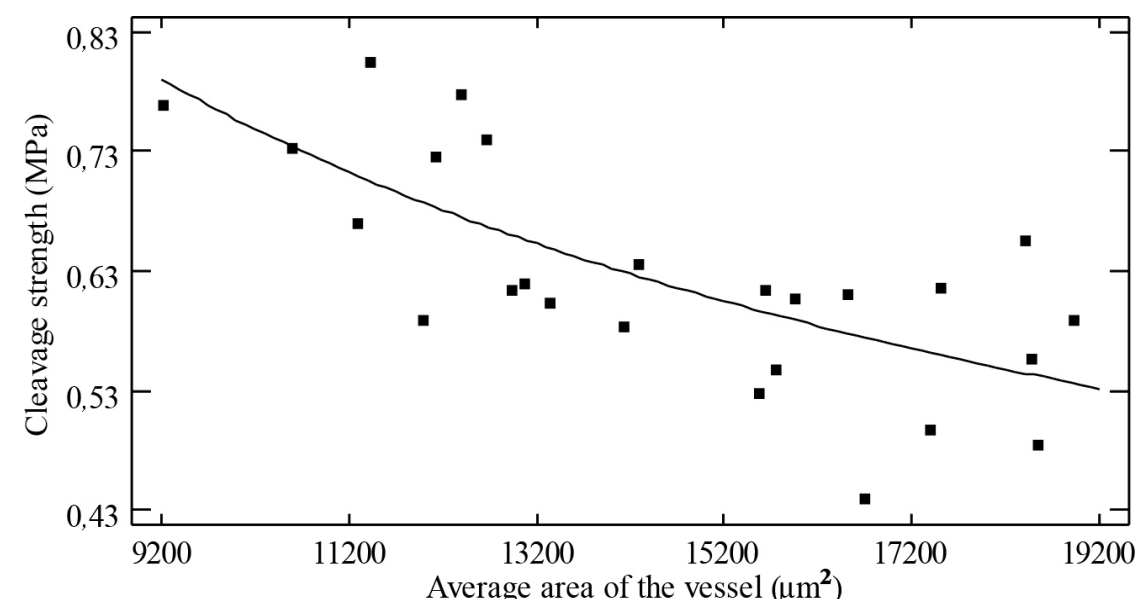

Figure 2: Behavior of the cleavage strength as a function of the average area of the vessel in Eucalyptus grandis sampled at 22 years of age.

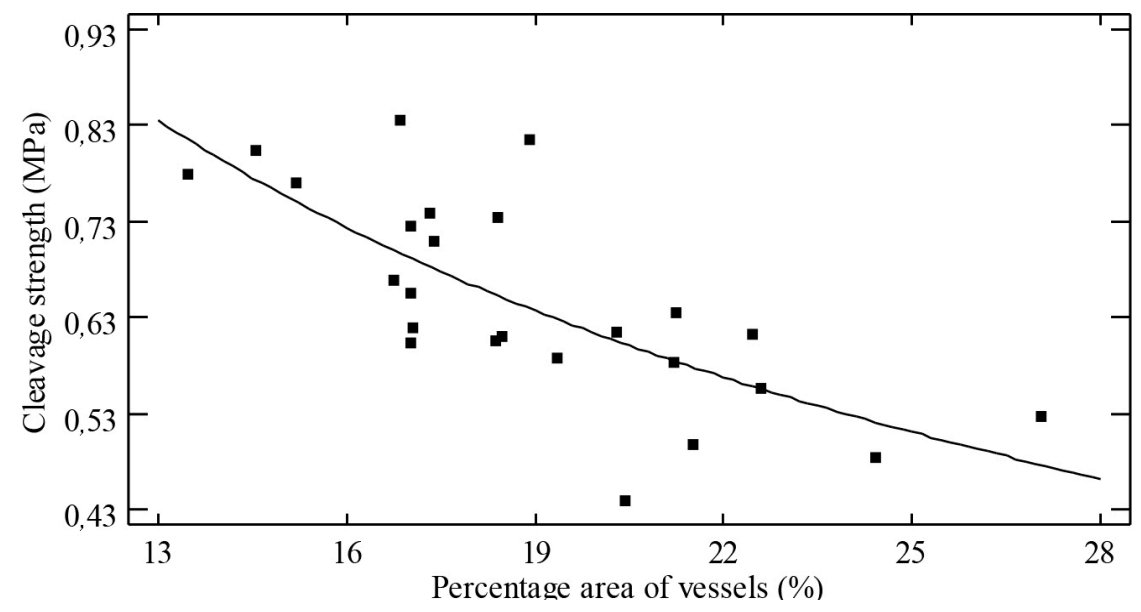

Figure 3: Behavior of the cleavage strength as a function of the percentage area of vessels in Eucalyptus grandis sampled at 22 years of age. 
The adjusted models were tested and presented significance at a $1 \%$ probability of error, as shown in Table 2 and Table 3.

Table 2: Analysis of variance of the linear regression adjusted for the cleavage strength as a function of the average area of the vessel in E. grandis wood.

\begin{tabular}{|c|c|c|c|}
\hline Source & Degrees of freedom & Mean square & Calculated F \\
\hline Model & 1 & 0,185455 & $27,72122^{*}$ \\
\hline Residual & 28 & 0,006690 & \\
\hline Total & 29 & & \\
\hline \multicolumn{3}{|c|}{$*$ significant at $1 \%$ probability of error. }
\end{tabular}

Table 3: Analysis of variance of the linear regression adjusted for the cleavage strength as a function of the percentage area of vessels in E. grandis wood.

\begin{tabular}{|c|c|c|c|}
\hline Source & Degrees of freedom & Mean square & Calculated F \\
\hline Model & 1 & 0,058348 & $26,75286^{*}$ \\
\hline Residual & 28 & 0,002181 & \\
\hline Total & 29 & & \\
\hline \multicolumn{2}{|c|}{ * significant at 1 \% probability of error. }
\end{tabular}

The behaviors seen in Figure 2 and Figure 3 indicate that there is an inverse relationship between the parameters of the vessels evaluated in the present study and the wood cleavage strength. Based on this, it is possible to infer that the higher the average area of the vessel and the higher the percentage area occupied by the vessels on the wood transverse surface, the higher the occurrence of $\mathrm{I}_{T L}$ type checks. These results corroborate those found by Gacitúa et al. (2007), Valenzuela et al. (2012a) and, Valenzuela et al. (2012b), who observed a higher intensity of checks in the woods that presented higher AAV. These statements also support what was said by Ugural and Fenster (1995), Craig (2011) and Sanford (2003) regarding the concentration of stresses at the edges of orifices contained in solids.

Based on the results observed for the cleavage strength as a function of AAV and PAV, a multiple linear regression model was adjusted for these parameters. Figure 4 illustrates the graphic behavior obtained from this analysis.

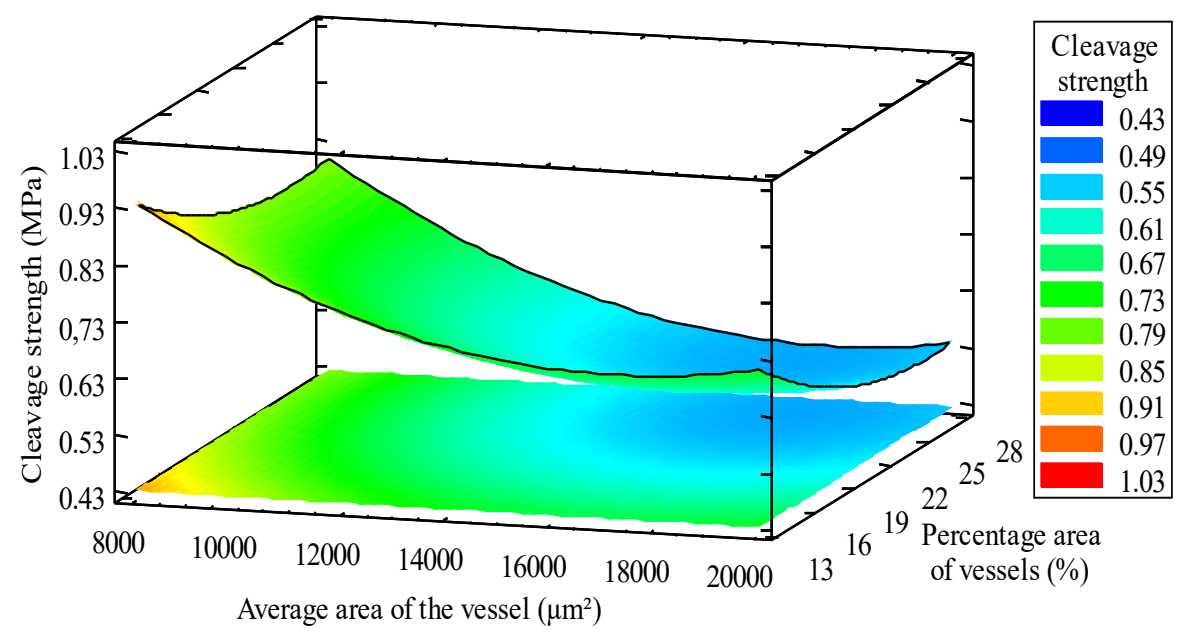

Figure 4: Behavior of the cleavage strength as a function of the average area of the vessel and percentage area of vessels in Eucalyptus grandis sampled at 22 years of age. 
Figure 4 clearly shows that the wood mechanical cleavage strength decreases when the average area of the vessels and the percentage of the transverse surface area occupied by vessels increases. In this way, the wood will tend to be less prone to checks when the area occupied by vessels in the wood is smaller.

Equation 5 presents the multiple regression model adjusted to estimate cleavage strength as a function of AAV and PAV.

$$
f_{s 0}=\left[-0,0908399+\left(2,93633 \times 10^{7}\left(\mathrm{AAV}^{-2}\right)\right)+\left(51,0006\left(\mathrm{PAV}^{-2}\right)\right)\right]^{0,5}
$$

Table 4 shows the significance test of the parameters used to adjust the model.

Table 4: Significance test of the parameters of the multiple linear regression model (Equation 11) using Student's t-statistic.

\begin{tabular}{|c|c|c|}
\hline Parameter & Estimate & t-statistic \\
\hline Percentage area of vessels $\left(\mathrm{PAV}^{-2}\right)$ & 51,0006 & $2,99458^{*}$ \\
\hline Average area of the vessel $\left(\mathrm{AAV}^{-2}\right)$ & $2,93633,10^{7}$ & $4,00115^{*}$ \\
\hline Constant & 0,0908399 & $1,82443^{\text {ns }}$ \\
\hline
\end{tabular}

* significant at $1 \%$ probability of error; ns = not significant.

The variable that most contributed to the adjustment of the multiple regression model was AAV, while PAV contributed less. This inference is based on the Student's t-statistic shown in Table 4, which indicates a lower contribution of the parameter to the model when the calculated $t$-value is closer to zero.

Table 5 shows that the regression is significant at a $1 \%$ probability of error. The coefficient of determination $\left(\mathrm{R}^{2}\right)$ of the model is equal to 0,675 and the adjusted coefficient of determination ( $\mathrm{R}^{2}$ adj.) is equal to 0,645 .

Table 5: Analysis of variance of the multiple regression adjusted for cleavage strength as a function of the average area of the vessel and percentage area of vessels in E. grandis wood.

\begin{tabular}{|c|c|c|c|}
\hline Source & Degrees of freedom & Mean square & Calculated F \\
\hline Model & 2 & 0,11448 & $22,82^{*}$ \\
\hline Residual & 27 & 0,00501702 & \\
\hline Total & 29 & & \\
\hline
\end{tabular}

* significant at $1 \%$ probability of error.

The $\mathrm{R}^{2}$ found in the multiple linear regression analysis is higher than the $\mathrm{R}^{2}$ of the simple linear regressions adjusted for each parameter separately. It is interesting that the multiple regression model had a better fit than the simple regression models, taking into account that the multiple regression model is considered more complex because it involves two independent variables. It can be said that the multiple regression model was able to estimate the cleavage strength more accurately based on the average area of the vessel, and percentage area of vessels, because it is more complete than simple regression models.

\section{CONCLUSIONS}

Eucalyptus grandis wood, analyzed at 22 years of age, has an average cleavage strength of $0,64 \mathrm{MPa}$. The average area of the vessel in this wood is $12493 \mu \mathrm{m}^{2}$, while the average percentage area occupied by vessels on the transverse surface is $18,7 \%$.

Vessel parameters are inversely related to cleavage strength, pointing out that the higher the average area of the vessel and the percentage area occupied by vessels on the transverse surface, the more prone the wood 
tends to be to the incidence of checks of the $\mathrm{I}_{T L}$ type.

The multiple linear regression model is able to estimate the cleavage strength as a function of the average area of the vessel, and the percentage area of vessels, with higher precision than the simple linear regression models adjusted from these independent variables separately.

\section{REFERENCES}

ASTM. 2014. Standard methods of testing small clear specimens of timber. ASTM D143-14. 2014. ASTM: West Conshohocken, PA, USA. http://dx.doi.org/10.1520/D0143-14

Araújo, H.J.B. 2007. Relações funcionais entre propriedades físicas e mecânicas de madeiras tropicais brasileiras (in Portuguese). Floresta 37(3): 399-416. http://dx.doi.org/10.5380/rf.v37i3.9937

Barotto, A.J.; Monteoliva, S.; Gyenge, J.; Martinez-Meier, A.; Moreno, K.; Tesón, N.; Fernández, M.E. 2017. Wood density and anatomy of three Eucalyptus species: implications on hydraulic conductivity. Forest Systems 26(1): 11-21. https://doi.org/10.5424/fs/2017261-10446

Bodig, J.; Jayne, B.A. 1982. Mechanics of wood and wood composites. V.N. Reinhold: New York, USA.

Carlquist, S. 2001. Comparative wood anatomy: systematic ecological, and evolutionary aspects of dicotyledon wood. 2 ed. Springer-Verlag: Berlin, DE. https://dx.doi.org/10.1007/978-3-662-04578-7

Craig, R.R. 2011. Mechanics of materials. 3 ed. Wiley, New Jersey, USA. https://www.wiley.com/en-us/ Mechanics + of + Materials\%2C+3rd+Edition-p-9780470481813

Dias, F.M.; Lahr, F.A.R. 2004. Estimativa de propriedades de resistência e rigidez da madeira através da densidade aparente (in Portuguese). Scientia forestalis 65: 102-113. https://www.ipef.br/publicacoes/scientia/ nr65/cap10.pdf

Downes, G.M.; Hudson, I.L.; Raymond, C.A.; Dean, G.H.; Michell, A.J.; Schimleck, L.R.; Evans, R.; Muneri, A. 1997. Sampling plantation Eucalypts for wood and fibre properties. CSIRO Publishing: Melbourne, AU. http://dx.doi.org/10.1071/9780643105287

Gacitúa, E.W.; Ballerini, A.A.; Lasserre, J.P.; Bahr, D. 2007. Nanoindentaciones y ultraestructura en madera de Eucalyptus nitens con micro y meso fracturas (in Spanish). Maderas-Cienc Tecnol 9(3): 259-270. http://dx.doi.org/10.4067/S0718-221X2007000300006 loads

ImageJ. 2019. ImageJ software Version 1.52p. National Institutes of Health. https://imagej.net/Down-

Mattheck, C.; Kubler, H. 1997. Wood: the internal optimization of trees. Springer-Verlag: New York, USA. http://dx.doi.org/10.1007/978-3-642-61219-0

Sanford, R.J. 2003. Principles of fracture mechanics. Prentice Hall: New Jersey, USA.

Soares, B.C.D.; Lima J.T.; Rocha, M.F.V.; Araújo, A.C.C.; Veiga, T.R.L.A. 2019. Behavior of juvenile and mature Eucalyptus cloeziana wood subjected to drastic drying. Floresta e Ambiente 26(3): e20170872. http://dx.doi.org/10.1590/2179-8087.087217

Ugural, A.C.; Fenster, S.K. 1995. Advanced strength and applied elasticity. 3 ed. Prentice Hall: New Jersey, USA.

Valenzuela C.P.; Bustos A.C.; Lasserre, J.P.; Gacitua E.W. 2012a. Fracturas en madera de Eucalyptus nitens: Efecto de las propiedades mecánicas a nivel ultraestructural y de la anatomía celular. Maderas-Cienc Tecnol 14(2): 225-238. http://dx.doi.org/10.4067/S0718-221X2012000200009

Valenzuela, C.P.; Bustos, A.C.; Lasserre, J.P.; Gacitua, E.W. 2012b. Caracterización nanomecánica de la estructura celular y anatómica de Eucalyptus nitens y su relación con la frecuencia de grietas y rajaduras en madera redonda. Maderas-Cienc Tecnol 14(3): 321-337. http://dx.doi.org/10.4067/S0718-221X2012005000006 